\title{
Función de la concentración sérica de interleucina 6 y proteína C-reactiva para diferenciar la etiología de la septicemia neonatal
}

\author{
The role of serum interleukin-6 and C-reactive protein levels for differentiating \\ aetiology of neonatal sepsis
}

\author{
Dr. Istemi H. Celik ${ }^{a}$, Dra. Gamze Demirel ${ }^{b}$, Dra. Nurdan Uras', Dra. Serife S. Oguzc , Dr. Omer Erdeved y \\ Dr. Ugur Dilmen ${ }^{c, e}$
}

\begin{abstract}
RESUMEN
Introducción. En la práctica clínica, hemos observado una concentración elevada de interleucina 6 (IL-6) en los casos de septicemia por gramnegativos.

Objetivo. Investigar la relación entre las concentraciones de IL-6 y proteína C-reactiva (PCR) y la determinación temprana de la septicemia neonatal por gramnegativos o grampositivos. Población y métodos. Se compararon el recuento de leucocitos y las concentraciones de IL-6 y PCR entre los distintos grupos. Resultados. Los grupos de infección por gramnegativos, infección por grampositivos y micosis estaban formados por 73,82 y 15 pacientes, respectivamente. Los valores de corte ideales de IL-6 entre el grupo de infección por gramnegativos y el de infección por grampositivos y el de micosis eran 202 $\mathrm{pg} / \mathrm{ml} \mathrm{y} 57 \mathrm{pg} / \mathrm{ml}$, respectivamente. En el grupo de micosis se observaron concentraciones dePCR más altas que en los grupos de infección por gramnegativos e infección por grampositivos. Conclusiones. Hasta donde sabemos, estees el estudio demayor envergadura notificado con el objetivo de determinar los valores de corte de IL-6 para diferenciar la etiología de la septicemia neonatal. Los microorganismos gramnegativos provocaron una producción de IL-6 diez veces mayor. La evaluación de IL-6 y PCR resulta útil para diagnosticar, y asimismo diferenciar, la etiología de la septicemia neonatal.

Palabras clave: recién nacido, septicemia, interleucina 6, proteína $C$-reactiva, infecciones por gramnegativos, micosis.
\end{abstract}

http:/ /dx.doi.org/10.5546/aap.2015.534

a. Neonatología, Hospital Universitario y de Investigación en Ginecología Etlik Zubeyde Hanim, Ankara.

b. Neonatología, Medipol Üniversitesi, Estambul.

c. Neonatología, Hospital Universitario Maternal Zekai Tahir Burak, Ankara.

d. Neonatología, Facultad de Medicina, Ankara Üniversitesi, Ankara.

e. Yıldırım Beyazıt Üniversitesi. Turquía.

Correspondencia:

Dr. Istemi H. Celik: istemihancelik@gmail.com

Financiamiento: Ninguno.

Conflicto de intereses: Ninguno que declarar.

Recibido: 29-5-2015

Aceptado: 10-8-2015

\section{INTRODUCCIÓN}

La septicemia neonatal sigue siendo una carga asistencial frecuente y significativa debido a los elevados índices de morbimortalidad a pesar de los avances en neonatología, especialmente en los países en vías de desarrollo. ${ }^{1}$ Se han utilizado diversas interleucinas, el factor de necrosis tumoral (FNT), la procalcitonina (PCT), la proteína C-reactiva (PCR), las inmunoglobulinas y otros marcadores para el diagnóstico de la septicemia. $^{2}$

Por lo tanto, reconocer los signos de infección tempranamente sobre la base de análisis clínicos o de laboratorio durante las primeras etapas de la septicemia ayuda a identificar a los pacientes que probablemente tengan una infección por microbios patógenos gramnegativos o grampositivos. De manera interesante, en algunos estudios se demostró una respuesta inflamatoria significativamente mayor en la septicemia por gramnegativos que en los casos de septicemia por grampositivos. ${ }^{3-5}$ Las micosis también presentan respuestas inflamatorias diferentes. ${ }^{6}$ Recientemente, observamos concentraciones elevadas de IL-6 en algunos recién nacidos con septicemia. Durante el seguimiento, según los resultados, la mayoría de estos pacientes tenía una infección por microorganismos gramnegativos. Tras dicha observación clínica, se decidió realizar un análisis de subgrupos con los datos obtenidos de un estudio publicado previamente en el cual se informaban valores de corte de IL-6 y PCR en la septicemia neonatal. ${ }^{7}$

\section{OBJETIVO}

1. investigar el valor de la IL-6 y la PCR para establecer tempranamente la etiología de la septicemia neonatal como gramnegativa o grampositiva,

2. determinar el valor de corte de cada marcador de septicemia neonatal,

3. identificar la sensibilidad, la especificidad, el valor predictivo positivo (VPP) y el valor predictivo negativo (VPN) de cada valor de corte. 


\section{MÉTODOS \\ Pacientes}

Este estudio retrospectivo se llevó a cabo en el Hospital Universitario Maternal Zekai Tahir Burak entre enero y diciembre de 2008; se revisaron las historias clínicas y se obtuvo la aprobación del Comité de Ética local. Se requerían, al menos, tres de los siguientes hallazgos clínicos para el diagnóstico de septicemia: bradicardia $(<100 / \mathrm{min})$, taquicardia ( $>200 / \mathrm{min})$, hipotensión, hipotonía, convulsiones, apnea, taquipnea, cianosis, dificultad respiratoria, color y perfusión de la piel inusuales, dificultad para alimentarse, irritabilidad, letargo y análisis de laboratorio con concentraciones elevadas de IL-6 $(>70 \mathrm{pg} / \mathrm{ml})$ o PCR (>10 mg/dl). ${ }^{8}$

\section{Criterios de inclusión en los grupos}

- Grupo Ia (septicemia confirmada; 170 pacientes): recién nacidos con hemocultivos positivos, signos clínicos de infección y concentración elevada de IL-6 o PCR.

- Grupo Ib (septicemia clínica; 62 pacientes): recién nacidos con signos clínicos de infección y concentración elevada de IL-6 o PCR, pero con hemocultivos negativos.

- Grupo II (grupo de referencia; 50 pacientes): concentración de IL-6 y PCR de recién nacidos hospitalizados debido a factores de riesgo perinatales, tales como desprendimiento prematuro de placenta, incompatibilidad Rh, situación fetal transversa o enfermedades no infecciosas, tales como hipoglucemia, restricción del crecimiento intrauterino, taquipnea transitoria, hiperbilirrubinemia indirecta, sin signos clínicos de infección.

\section{Análisis estadísticos}

Se utilizó el paquete estadístico SPSS (v.15.0) para realizar los análisis estadísticos. Se usó la prueba $\chi^{2}$ para analizar las variables categóricas.
Las medias se compararon con la prueba $t$ cuando los datos se ajustaban a una distribución normal, o con la prueba de la $U$ de Mann-Whitney cuando los datos eran anormales. Para comparar más de dos grupos, se utilizó un ANOVA para las distribuciones normales, y la prueba de KruskalWallis para las distribuciones anormales. Se usó el análisis de la curva ROC para determinar la potencia de las variables para diferenciar los grupos, y se calculó el área bajo la curva; los valores de corte significativos se calcularon mediante el índice de Youden. Un valor de $p<0,05$ se consideró estadísticamente significativo.

\section{RESULTADOS}

Hubo 232 pacientes en el grupo I, y 50 en el grupo II. Las características de los pacientes y su distribución dentro de los grupos se indican en la Tabla 1. No se observaron diferencias estadísticas en cuanto a la edad gestacional, el peso al nacer, la proporción de varones y mujeres, y el índice de parto vaginal. El día del análisis de diagnóstico con IL-6 y PCR fue similar entre los grupos de septicemia confirmada y septicemia clínica, aunque fue anterior en el grupo de referencia. En la Tabla 2 se presentan los resultados de los hemocultivos, en los cuales se aislaron 29 tipos de microorganismos. La cantidad de microorganismos gramnegativos, microorganismos grampositivos y hongos fue $73(43 \%), 82(48 \%)$ y $15(9 \%)$, respectivamente. Los microorganismos aislados con mayor frecuencia fueron Klebsiella pneumoniae (44; 25,8\%), Staphylococcus epidermidis (29; 17\%), hongos (Candida albicans y Candida tropicalis, 15; 8,8\%), y Staphylococcus aureus (10; 5,8\%).

Previamente, habíamos hallado valores de corte de IL-6 y PCR entre el grupo de septicemia confirmada y el grupo de referencia de $21,5 \mathrm{pg} \mathrm{ml}$ y $5,82 \mathrm{mg} / \mathrm{dl}$, respectivamente. ${ }^{7}$ Las concentraciones de IL-6 y PCR en todos los grupos se pre-

TABLA 1. Características clínicas y demográficas de los grupos de septicemia confirmada, septicemia clínica y referencia

\begin{tabular}{lccc}
\hline & Grupo Ia (n= 170) & Grupo Ib (n= 62) & Grupo II (n= 50) \\
\hline Varones/mujeres & $87 / 82$ & $38 / 24$ & $30 / 20$ \\
Día de análisis de diagnóstico de septicemia & $14,3 \pm 10,0$ & $14,8 \pm 10,2$ & $3,9 \pm 3,4$ \\
Peso al nacer, en gramos & $1580 \pm 685$ & $1585 \pm 718$ & $1735 \pm 760$ \\
Edad gestacional, en semanas & $30,6 \pm 3,4(23-41)$ & $30,8 \pm 3,6(24-38)$ & $31,7 \pm 3,9(25-42)$ \\
Parto vaginal,\% & 27,6 & 24,2 & 30,6 \\
Edad materna, en años & $26,8 \pm 5,2$ & $27,7 \pm 6,7$ & $28,4 \pm 6,1$ \\
\hline
\end{tabular}

media \pm desviación estándar (rango intercuartilo). 
sentan en la Tabla 3. Se observaron diferencias significativas entre los grupos de septicemia y el de referencia, tanto en las concentraciones de IL-6 como de PCR $(p<0,001)$. Las concentraciones de

TABLA 2. Resultados de asilamiento microbiológico en hemocultivos

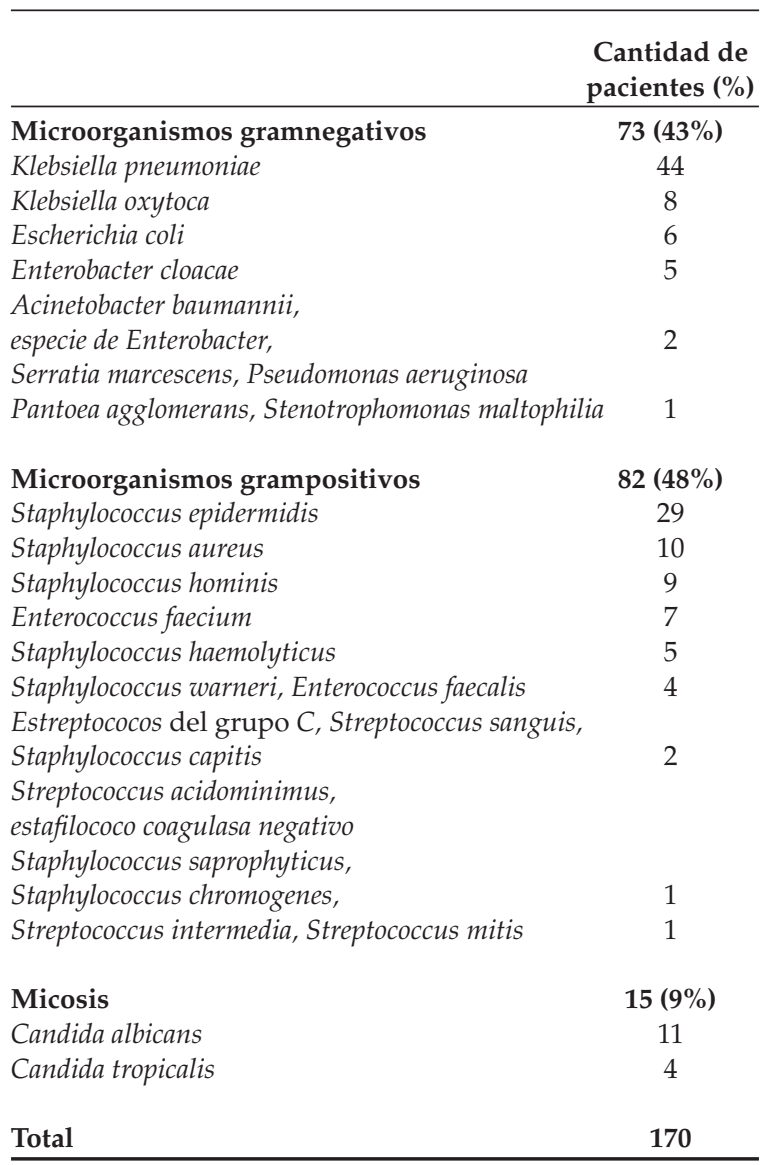

IL-6 y PCR en los grupos de infección por gramnegativos, infección por grampositivos y micosis se presentan en la Tabla 4. Se observaron diferencias estadísticamente significativas entre el grupo de infección por gramnegativos y los demás grupos según la concentración de IL-6 $(p<0,001)$. Se halló que los valores de corte ideales de IL-6 para el diagnóstico de infección por gramnegativos eran $202 \mathrm{pg} / \mathrm{ml}$ frente a la infección por grampositivos, y $57 \mathrm{pg} / \mathrm{ml}$ frente a la micosis.

Se halló que el valor de corte ideal de IL-6 para el diagnóstico de infección por grampositivos frente a la micosis era $58 \mathrm{pg} / \mathrm{ml}$. La sensibilidad, la especificidad, el VPN y el VPP de una concentración de IL-6 de 202 pg/ml (infección por gramnegativos frente a infección por grampositivos) son $68 \%, 58 \%, 57 \%$ y $69 \%$, respectivamente. La sensibilidad, la especificidad, el VPN y el VPP de una concentración de IL-6 de 57 pg/ml (infección por gramnegativos frente a micosis) son $76 \%, 42 \%, 24 \%$ y $71 \%$, respectivamente. La sensibilidad, la especificidad, el VPN y el VPP de una concentración de IL-6 de 58 pg/ml (infección por grampositivos frente a micosis) son $76 \%, 29 \%$, $27 \%$ y $55 \%$, respectivamente. En el grupo de micosis se observaron concentraciones de PCR más altas que en los otros grupos $(p<0,05)$. Los índices de mortalidad en los grupos de infección por gramnegativos, infección por grampositivos y micosis fueron $18 \%, 10 \%$ y $20 \%$, respectivamente $(p>0,05)$.

No se observaron diferencias estadísticamente significativas entre los grupos en cuanto a hemoglobina y recuento de leucocitos $(p>0,05)$. Los recuentos de trombocitos de los grupos de referencia, infección por gramnegativos, infección

TABLA 3. Concentraciones de IL-6 y PCR de los grupos de septicemia confirmada, septicemia clínica y referencia (media \pm desviación estándar)

\begin{tabular}{lcccc}
\hline & $\begin{array}{c}\text { Grupo Ia } \\
\text { (septicemia confirmada) } \\
(\mathbf{n}=\mathbf{1 7 0})\end{array}$ & $\begin{array}{c}\text { Grupo Ib } \\
\text { (septicemia clínica) } \\
(\mathbf{n = 6 2 )}\end{array}$ & $\begin{array}{c}\text { Grupo II } \\
\text { (referencia) } \\
(\mathbf{n = 5 0 )}\end{array}$ & $p$ \\
\hline IL-6 $(\mathrm{pg} / \mathrm{ml})$ & $349 \pm 422$ & $257 \pm 358$ & $35 \pm 104$ & $<0,001$ \\
PCR $(\mathrm{mg} / \mathrm{dl})$ & $18,2 \pm 14,5$ & $13,6 \pm 13,5$ & $1,6 \pm 2,6$ & $<0,001$ \\
\hline
\end{tabular}

TABLA 4. Concentraciones de IL-6 y PCR de los grupos de infección por gramnegativos, infección por grampositivos, micosis y referencia (media \pm desviación estándar)

\begin{tabular}{lcccc} 
Grupo de infección & $\begin{array}{c}\text { Por gramnegativos } \\
(\mathbf{n}=\mathbf{7 3})\end{array}$ & $\begin{array}{c}\text { Por grampositivos } \\
(\mathbf{n}=\mathbf{8 2})\end{array}$ & $\begin{array}{c}\text { Micosis } \\
(\mathbf{n}=\mathbf{1 5})\end{array}$ & $\begin{array}{c}\text { Referencia } \\
(\mathbf{n}=\mathbf{5 0})\end{array}$ \\
\hline IL-6 $(\mathrm{pg} / \mathrm{ml})$ & $500 \pm 439$ & $320 \pm 418$ & $45 \pm 64$ & $35 \pm 104$ \\
PCR $(\mathrm{mg} / \mathrm{dl})$ & $19 \pm 14,2$ & $17,9 \pm 14,9$ & $22,6 \pm 13$ & $1,6 \pm 2,6$ \\
\hline
\end{tabular}


por grampositivos y micosis fueron $199 \times 10^{3}$ $\pm 131 \times 10^{3}, 153 \times 10^{3} \pm 126 \times 10^{3}, 207 \times 10^{3} \pm 138$ $\times 10^{3}, 101 \times 10^{3} \pm 79 \times 10^{3} / \mu 1$. Conforme a los recuentos de trombocitos, la concentración de trombocitos fue menor en los grupos de infección por gramnegativos y micosis, en comparación con los grupos de referencia e infección por grampositivos $(p<0,05)$. En el grupo de micosis se observó una menor concentración de trombocitos que en el grupo de infección por gramnegativos $(p<0,05)$.

\section{DISCUSIÓN}

La IL-6 es una importante citocina de la respuesta temprana del huésped a una infección. Tras la exposición a productos bacterianos, la concentración de IL-6 aumenta rápidamente y produce el aumento de PCR. Su semivida es muy breve, y la concentración disminuye con el tratamiento hasta volverse indetectable en la mayoría de los pacientes infectados dentro de las 24 horas. El hígado sintetiza la PCR en un lapso de 6 a 8 horas en la respuesta inflamatoria, llega a su concentración máxima a las 24-48 horas y se reduce con el tiempo a medida que se resuelve la inflamación.

Las diferencias en los mecanismos de la virulencia bacteriana producen diferencias en la respuesta del huésped, el alcance de la activación de diversas cascadas de señalización y la estimulación/inhibición de la apoptosis del huésped, que influyen en el pronóstico., ${ }^{9,10}$ Ya se han reconocido los patrones moleculares asociados a patógenos (PMAP). ${ }^{11}$ Se sabe que los PMAP de las bacterias gramnegativas y grampositivas actúan como ligandos de receptores de reconocimiento de patrones mutuamente diferentes, incluidos los receptores de tipo Toll. ${ }^{12}$

En nuestro estudio se demostró que los microorganismos gramnegativos produjeron un aumento del valor de corte de la IL-6 diez veces mayor, en comparación con el grupo de septicemia confirmada general. Aparentemente, la micosis causa una menor producción de citocina. Los estudios sobre la previsibilidad de los tipos de microorganismos según las citocinas se realizan mayormente en adultos. Previamente, Fisher y col., informaron que la concentración plasmática de IL-6 era significativamente más alta en los pacientes con septicemia por gramnegativos y predice un desenlace mortal. ${ }^{13}$ Abe y col., demostraron que las concentraciones de IL-6 y PCR eran mayores en los casos de septicemia por gramnegativos en la unidad de cuidados intensivos. ${ }^{3}$ Observaron que la incidencia de septicemia por gramnegativos y la mortalidad eran significativamente mayores en el grupo de choque septicémico que en los grupos de septicemia y septicemia grave.

En los niños con septicemia, se halló que la IL-6 predijo la mortalidad de mejor manera que los análisis clínicos u otros análisis de laboratorio. ${ }^{14}$ En nuestro estudio, el índice de mortalidad del grupo de infección por gramnegativos fue levemente mayor que en el grupo de infección por grampositivos, sin que se observaran diferencias estadísticas. Kumar y col., demostraron que la concentración de FNT- $\alpha$ era mayor en los casos pediátricos de septicemia por gramnegativos que por grampositivos, aunque no hallaron diferencias en la concentración de PCR en la población del estudio. ${ }^{15}$

Los pacientes con septicemia por micosis tienen una concentración menor de IL-6 que aquellos en los grupos de septicemia por gramnegativos y grampositivos, aunque cabe destacar que su concentración de PCR es mayor. Previamente, Oguz y col., informaron una concentración elevada de PCR en pacientes con septicemia por micosis y demostraron que debe sospecharse la presencia de esta entidad en los pacientes con una persistente concentración elevada de PCR ${ }^{6}$

El comienzo del tratamiento de la septicemia neonatal es empírico y abarca microorganismos tanto gramnegativos como grampositivos. Si se determina la etiología, es posible instaurar el tratamiento correspondiente. Estos hallazgos sugieren que deben considerarse las diferencias en las respuestas del huésped y los mecanismos de virulencia de los distintos microorganismos patógenos al establecer el tratamiento de los pacientes con septicemia. Nuestros datos tal vez ayuden a los médicos a instaurar el tratamiento adecuado y predecir el desenlace.

A modo de conclusión, consideramos que la IL-6 y la PCR sirven para determinar la etiología de la septicemia neonatal e implementar el tratamiento empírico de esta.

\section{REFERENCIAS}

1. Osrin D, VergnanoS, Costello A. Serious bacterial infections in newborn infants in developing countries. Curr Opin Infect Dis 2004;17(3):217-24.

2. Khassawneh M, Hayajneh WA, Kofahi H, Khader Y, et al. Diagnostic markers for neonatal sepsis: comparing C-reactive protein, interleukin-6 and immunoglobulin $\mathrm{M}$. Scand J Immunol 2007;65(2):171-5.

3. Abe R, Oda S, Sadahiro T, Nakamura M, et al. Gramnegative bacteremia induces greater magnitude of 
inflammatory response than Gram-positive bacteremia. Crit Care 2010;14(2):R27.

4. HeneyD,LewisIJ,EvansSW, BanksR, etal.Interleukin-6 and its relationship to C-reactive protein and fever in children with febrile neutropenia. J Infect Dis 1992;165(5):886-90.

5. Vandijck DM, Hoste EA, Blot SI, Depuydt PO, et al. Dynamics of C-reactive protein and white blood cell count in critically ill patients with nosocomial Gram positive vs. Gram negative bacteremia: a historical cohort study. BMC Infect Dis 2007:7:106.

6. Oguz SS, Sipahi E, Dilmen U. C-reactive protein and interleukin-6 responses for differentiating fungal and bacterial aetiology in late-onset neonatal sepsis. Mycoses 2011;54(3):212-6

7. Celik IH, Demirel FG, Uras N, Oguz SS, et al. What are the cut-off levels for IL-6 and CRP in neonatal sepsis? J Clin Lab Anal 2010;24(6):407-12.

8. Haque KN. Definitions of bloodstream infection in the newborn. Pediatr Crit Care Med 2005;6(3 Suppl):S45-9.

9. Webb SA, Kahler CM. Bench-to-bedside review: Bacterial virulence and subversion of host defences. Crit Care 2008;12(6):234.
10. Finlay BB, McFadden G. Anti-immunology: evasion of the host immune system by bacterial and viral pathogens. Cell 2006;124(4):767-82

11. Lotze MT, Zeh HJ, Rubartelli A, Sparvero LJ, et al. The grateful dead: damage-associated molecular pattern molecules and reduction/oxidation regulate immunity. Immunol Rev 2007;220:60-81.

12. AkiraS, UematsuS, TakeuchiO. Pathogen recognition and innate immunity. Cell 2006;124(4):783-801.

13. Fisher CJ Jr, Opal SM, Dhainaut JF, Stephens S, et al. Influence of an anti-tumor necrosis factor monoclonal antibody on cytokine levels in patients with sepsis. The CB0006 Sepsis Syndrome Study Group. Crit Care Med 1993;21(3):318-27.

14. Sullivan JS, Kilpatrick L, Costarino AT Jr, Lee SC, et al. Correlation of plasma cytokine elevations with mortality rate in children with sepsis. J Pediatr 1992;120(4 Pt 1):510-5.

15. Kumar S, Rizvi M. Serum tumor necrosis factor alpha and C-reactive protein in pediatric patients with sepsis and its correlation with microbiologic findings. Indian J Pathol Microbiol 2010;53(3):494-7.

\title{
Utilidad del diagnóstico por componentes en el seguimiento de niños con alergia a alimentos vegetales
}

\author{
Use of component-resolved diagnosis in the follow-up of children with plant food \\ allergy
}

\author{
Lic. Olga Villarreal Balza De Vallejo ${ }^{a}$, Lic. Marta Velasco Azagra ${ }^{a}$, Lic. Amanda López Picado \\ Lic. Nagore Bernedo Belar ${ }^{a}$, Dra. Olga Uriel Villate ${ }^{a}$, Lic. Marta Frías Jiménez ${ }^{a}$, Dra. Maite Audicana \\ Berasategui ${ }^{a}$, Lic. Daniel Muñoz Lejarazu ${ }^{a \dagger}$, Lic. Nagore Arruti Oyarzabal ${ }^{a}$, Lic. Italo N. Girao Popolizio ${ }^{a}, y$ \\ Lic. Ana Martínez Arcediano ${ }^{a}$ \\ Colaboradores: Lic. Natividad Longo Areso y Lic. Eduardo Fernández Ibañez
}

\section{RESUMEN}

La alergia a los alimentos representa un problema importante en la edad pediátrica. El diagnóstico por componentes detecta la alergia a proteínas aisladas de los alimentos.

a. Servicio de Alergología, Hospital Universitario Araba, Vitoria-Gasteiz, España.

b. Unidad de Investigación Araba. Hospital Universitario Araba, Vitoria-Gasteiz, España.

Correspondencia:

Lic. Olga Villarreal: mariaolga.villarrealbalzadevallejo@ osakidetza.net

Financiamiento: Ninguno.

Conflicto de intereses: Ninguno que declarar.

Recibido: 8-1-2015

Aceptado: 19-6-2015
Este estudio descriptivo analiza la utilidad de las recomendaciones individualizadas y estandarizadas en una muestra de 22 niños de entre 2 y 16 años con alergia a alimentos vegetales y evalúa la sensibilidad a 4 panalergenos vegetales.

Según los resultados del diagnóstico por componentes, se personalizó el tratamiento, se aconsejaron pautas de evitación de determinados alimentos o componentes y se explicaron cofactores que favorecían las reacciones alérgicas alimentarias. No refirieron nuevas reacciones 20/22 casos. Presentaron síndrome alérgico oral $2 / 22$ pacientes alérgicos a profilina por no seguir las recomendaciones dadas.

El diagnóstico por componentes resultó útil en el diagnóstico y manejo de estos niños. Las recomendaciones estandarizadas, basadas en el diagnóstico por componentes implicado en cada paciente, evitaron reacciones alérgicas alimentarias graves. Palabras clave: diagnóstico por componentes, panalergeno, alergia, proteína transportadora de lípidos, niño.

http:/ /dx.doi.org/10.5546/aap.2015.538 


\section{INTRODUCCIÓN}

Las reacciones alérgicas a alimentos vegetales representan un desafío en la práctica alergológica pediátrica. Clásicamente, las recomendaciones se basan en la evitación del alimento causante de la alergia, ${ }^{1}$ lo que, en pacientes pediátricos, es difícil de aplicar y dificulta la adhesión al tratamiento.

El diagnóstico por componentes (componentresolved diagnosis; CRD, por sus siglas en inglés) permite detectar la alergia a proteínas individuales presentes en los alimentos y, en función de sus características fisicoquímicas, predecir los síntomas y evitarlos. ${ }^{1-4}$ Algunas de las proteínas alergénicas están expresadas en múltiples alimentos vegetales y en pólenes, y se denominan panalergenos vegetales. Entre ellos, se encuentran las proteínas de defensa de las plantas. Actualmente, solo algunas de ellas están disponibles para su aplicación en la clínica:

- Las proteínas transportadoras de lípidos (lipid transfer proteins; LTP, por sus siglas en inglés) presentes en pieles y cubiertas son resistentes a la pepsina y al calor, y pueden causar reacciones alérgicas en alimentos cocinados y procesados. ${ }^{5,6}$

- La proteína de polen de abedul Bet v1 (PR10) se relaciona con la alergia a la manzana, a la avellana, al apio y a la soja. ${ }^{7}$ Esta y la profilina ${ }^{4,8}$ son sensibles al calor y a la digestión, y por ello, los alimentos cocinados o procesados son tolerados. La manifestación clínica predominante es el síndrome de alergia oral.

- Las glicoproteínas de las plantas e invertebrados contienen glucanos con determinantes carbohidratos capaces de inducir síntesis de IgE específica en humanos. Esta sensibilización raramente se asocia a síntomas clínicos. Su existencia puede explicar algunos perfiles con amplia reactividad a diferentes alimentos. ${ }^{9}$

En los niños pequeños, las causas principales de alergia alimentaria son la leche $(2,5 \%)$, el huevo $(1,3 \%)$ y el cacahuete o maní $(0,8 \%)$, y en la mayoría, desaparecen en la edad escolar. ${ }^{10}$ En niños mayores, la alergia alimentaria es un problema importante ${ }^{10-12}$ de difícil manejo y comprensión para el médico y la familia, y muchas veces, es causa de retirada innecesaria de alimentos y añade riesgo de dificultad nutricional.

El objetivo principal de este estudio es describir la aplicación de las recomendaciones alimentarias basadas en el diagnóstico por componentes en 22 pacientes pediátricos.

\section{MATERIAL Y MÉTODOS}

Este es un estudio descriptivo retrospectivo, en el que incluimos a todos los pacientes consecutivos de entre 2 y 16 años que consultaron por reacciones adversas con alimentos vegetales con sospecha de base alérgica en la Unidad de Alergología del Hospital Universitario Araba (septiembre de 2009-marzo de 2011).

En la primera consulta de estos pacientes, se realizó un anamnesis, exploración, tests cutáneos, petición de analítico y cuestionario de tolerancia, y se indicaron normas dependiendo de los resultados preliminares. En la segunda, según el resultado del estudio alérgico, se entregaron normas de evitación/ingesta. A los 6 meses, en la consulta de revisión, se evaluó la respuesta a las indicaciones y cada paciente y/o cuidador fueron interrogados sobre los síntomas previamente relacionados y se realizó una anamnesis dirigida para detectar alergias alimentarias, definidas como la presencia de síntomas respiratorios, gástricos, cutáneos o anafilaxia en las 4 horas tras la ingesta del alimento. Si no había incidencias, los niños eran citados al año y, si se producían nuevas reacciones, eran derivados nuevamente.

La evolución y respuesta a las recomendaciones fueron evaluadas mediante la consulta presencial o la revisión de la historia clínica. En caso de que el paciente no hubiera acudido a la consulta o en los casos dudosos, se contactó telefónicamente a los familiares para constatar la evolución (marzo de 2013). La adherencia a las normas y la presencia de reacciones alérgicas alimentarias fue referida por el cuidador.

Se consideraron alérgicos si los pacientes presentaban prueba cutánea (pápula de, al menos, $3 \mathrm{~mm} \times 3 \mathrm{~mm}$ ) y/o por IgE específica positiva (mayor de $0,36 \mathrm{kU} / \mathrm{L})^{1}$ al alimento sospechoso de ser causante de la reacción. Las pruebas cutáneas utilizadas fueron el prick test y el prick-prick. El prick test consiste en depositar una gota del extracto alergénico que se va a probar sobre la piel del antebrazo y perforar la piel a través de esa gota mediante una lanceta. El prick-prick consiste en la punción cutánea tras hacerla en el alimento.

Para cada paciente, se determinó IgE específica y prueba cutánea (Tabla 1). Se aplicó un cuestionario de tolerancia a diferentes alimentos vegetales (más de 100 ítems) y se especificó el alimento y su estado (crudo/cocinado, pelado), junto con la anamnesis de cada reacción alérgica. Se anotaron los alimentos tolerados después y se evaluaron los cofactores, como ejercicio 
o toma de antiinflamatorios no esteroideos concomitantemente y antecedentes de polinosis.

Se clasificó a los pacientes en cuatro grupos según su sensibilización. Se consideró paciente sensibilizado a LTP a aquel con prueba cutánea positiva a LTP o con IgE específica frente a rPru p3 o rPar j. De igual manera, los pacientes con prueba cutánea positiva para profilina o con $\mathrm{IgE}$ específica positiva frente a $\mathrm{rPhl} \mathrm{p} 12 \mathrm{o}$ rBet v2 se consideraron sensibilizados a profilina, $y$ aquellos con respuesta positiva en IgE específica frente a rBet v1 fueron clasificados como sensibles a Bet v1. Finalmente, los pacientes con IgE frente a bromelina o MUXF3 se etiquetaron de sensibles a determinantes de reactividad cruzada de carbohidratos. Se definió como paciente monosensible si demostraba sensibilidad a uno de los cuatro panalergenos vegetales y como paciente polisensibilizado en caso de sensibilización concomitante a varios.

Sobre la base de la bibliografía previa, ${ }^{4,6,12,13}$ se entregaron por escrito normas de evitación de alimentos (completos o partes), condiciones de ingesta y evitación de cofactores ${ }^{14,15}$ según el panalergeno implicado (Tabla 2). En caso de no presentar sensibilidad a ninguno de los panalergenos, se recomendó eliminar de la dieta el alimento que tuvo una prueba cutánea positiva.

Las variables continuas se describieron mediante su media, mediana, desviación estándar y rango, y las categóricas, mediante su frecuencia y porcentaje. Todo el análisis se realizó con el programa SPSS Statistics (v. 19).

\section{RESULTADOS}

Se incluyeron en el estudio 22 pacientes; $13 / 22$ eran varones con edad media de $11,4 \pm 4,6$ años. $8 / 22$ tenían historia previa de alergia a alimentos y, en $7 / 22$ de los casos, se debía a frutos secos y/o frutas rosáceas; y el otro paciente (1/8) presentaba alergia al plátano. La mediana del seguimiento fue de 3 años (1,6-3,9 años) y no hubo pérdidas durante el mismo.

En $20 / 22$ casos, no se refirieron nuevas reacciones alérgicas a alimentos; los 2 pacientes que sí las presentaron eran alérgicos a la

TABLA 1. Pruebas cutáneas y determinaciones de IgE realizadas a los participantes

\begin{tabular}{|c|c|c|c|}
\hline \multicolumn{4}{|l|}{ Pruebas cutáneas } \\
\hline & Prick test & Producto - alérgeno & Laboratorio \\
\hline & Pru p3 & LTP de melocotón con $30 \mu \mathrm{g} / \mathrm{ml}$ de Prup3 & ALK-Abelló \\
\hline & Profilina & Profilina & ALK-Abelló \\
\hline & Frutos secos & $\begin{array}{l}\text { Cacahuete, avellana, almendra, semilla de girasol, } \\
\text { nuez, pistacho y piñón }\end{array}$ & LETI \\
\hline & Frutas & Melocotón (piel y pulpa) & ALK-Abelló \\
\hline & Frutas & Uva, melón, aguacate, fresa & LETI \\
\hline & Verduras & Puerro, perejil, lechuga, cardo, apio & LETI \\
\hline & Legumbres & Guisante & LETI \\
\hline & Harinas & Trigo y maíz & LETI \\
\hline & Pólenes & Betula, phleum, parietaria & LETI \\
\hline & Controles & Histamina & \\
\hline & & Suero fisiológico & \\
\hline & \multicolumn{3}{|l|}{ Técnica prick-prick } \\
\hline & Frutas & Manzana y pera (piel y pulpa), plátano, kiwi & \\
\hline & Legumbres & Alubia, soja, lenteja, garbanzo & \\
\hline & Verduras & Zanahoria, patata, cebolla, ajo, tomate & \\
\hline & Especias & $\begin{array}{l}\text { Pimienta negra, pimentón, clavo, nuez moscada, } \\
\text { comino, curry, laurel }\end{array}$ & \\
\hline \multicolumn{4}{|l|}{ IgE específica } \\
\hline & LTP & rPru p 3 y rPar j2 & \\
\hline & Profilinas & rPhp12 y Bet v2 & \\
\hline & CCD & Bromelina y MUXF3 & \\
\hline & PR-10 & rBet v1 & \\
\hline & Polen & Abedul, polen de gramíneas y malezas & \\
\hline & Alimentos implicados & & \\
\hline & en cada paciente & & \\
\hline
\end{tabular}

LTP: proteínas transportadoras de lípidos; CCD: determinantes de reactividad cruzada de carbohidratos. 
profilina y tuvieron reacciones tipo síndrome de alergia oral, sin necesidad de tratamiento de urgencia. Los episodios de alergia se debieron al incumplimiento de las normas indicadas. Los resultados principales se recogen en la Tabla 3.

El panalergeno más prevalente fue LTP $(13 / 22)$, solo o en polisensibilización, seguido de profilina $(9 / 22) ; 13 / 22$ fueron monosensibles (Tabla 4). En $3 / 22$ pacientes, no se detectó sensibilización a los panalergemo valorados. La sensibilización a las frutas rosáceas y a los frutos secos fue la más frecuente y su asociación se produjo en $7 / 22$ de los pacientes.

En los casos de alergia a LTP, los alimentos causantes de alergia fueron frutas rosáceas en $9 / 22$ niños y frutos secos en $5 / 22$. En los casos de alergia a la profilina, en 2 de los 3 niños estuvieron implicadas las frutas rosáceas.

\section{DISCUSIÓN}

El diagnóstico por componentes aplicado a la población pediátrica ha sido utilizado en el estudio de la alergia a alimentos $\operatorname{concretos}^{1,2} \mathrm{o}$ para el estudio de la alergia a pólenes, pero no hemos encontrado estudios que reflejaran la evolución de los pacientes tras el diagnóstico de alergia a alérgeno vegetal y aplicación de recomendaciones.

Los consejos han resultado eficaces, en especial los pacientes con alergia a LTP. La adhesión es alta, posiblemente porque no suponen alteraciones significativas en los hábitos o por los antecedentes de reacciones graves. Las reacciones referidas en pacientes con alergia a la profilina pueden deberse a que las recomendaciones son genéricas e implican prescindir de alimentos vegetales crudos. Como principalmente provocan síndrome de alergia oral, puede que los pacientes

TABla 2. Recomendaciones según el panalergeno

\begin{tabular}{|c|c|c|c|c|}
\hline Recomendaciones & LTP & Profilina & BET v1 & CCD \\
\hline Prohibiciones & $\begin{array}{l}\text { 1. Frutos secos } \\
\text { 2. Melocotón y } \\
\text { similares (nectarina, } \\
\text { albaricoque, paraguayo) } \\
\text { 3. Alimentos vegetales } \\
\text { implicados en cada } \\
\text { paciente y con los que } \\
\text { se hubiera confirmado } \\
\text { sensibilización en PC o } \\
\text { en IgE específica }\end{array}$ & $\begin{array}{l}\text { Alimentos vegetales } \\
\text { causantes de RAA en el } \\
\text { paciente y para los que } \\
\text { hubiera sensibilización } \\
\text { confirmada en PC o IgE } \\
\text { específica }\end{array}$ & $\begin{array}{c}\text { Alimentos vegetales } \\
\text { causantes de RAA en el } \\
\text { paciente y para los que } \\
\text { hubiera sensibilización } \\
\text { confirmada en PC o IgE } \\
\text { específica }\end{array}$ & $\begin{array}{c}\text { Pacientes con } \\
\text { monosensibilización: } \\
\text { evítense alimentos } \\
\text { implicados }\end{array}$ \\
\hline Evitación aconsejada & & $\begin{array}{l}\text { Melón, sandía, cítricos, } \\
\text { plátano, tomate }\end{array}$ & $\begin{array}{c}\text { Albaricoque, cereza, } \\
\text { manzana, melocotón, } \\
\text { pera, avellana almendra, } \\
\text { apio, zanahoria }\end{array}$ & $\begin{array}{c}\text { Pacientes con } \\
\text { polisensibilización: } \\
\text { se aplican las }\end{array}$ \\
\hline $\begin{array}{l}\text { Condiciones } \\
\text { de ingesta }\end{array}$ & $\begin{array}{l}\text { Evítense pieles y } \\
\text { cubiertas de frutas; } \\
\text { se deben comer } \\
\text { frutas peladas }\end{array}$ & $\begin{array}{l}\text { Ingesta de frutas, } \\
\text { verduras y zumos } \\
\text { cocinados o procesados }\end{array}$ & $\begin{array}{l}\text { Ingesta de frutas, } \\
\text { verduras y zumos } \\
\text { cocinados o procesados }\end{array}$ & $\begin{array}{l}\text { recomendaciones } \\
\text { establecidas para la otra } \\
\text { alergia concomitante }\end{array}$ \\
\hline Cofactores & $\begin{array}{l}\text { - Ejercicio } \\
\text { - AINE }\end{array}$ & & & \\
\hline $\begin{array}{l}\text { Tratamiento } \\
\text { disponible } \\
\text { recomendado }\end{array}$ & $\begin{array}{l}\text { Autoinyección } \\
\text { de adrenalina, } \\
\text { antihistamínico y } \\
\text { corticoide }\end{array}$ & $\begin{array}{c}\text { Antihistamínico y } \\
\text { corticoide oral }\end{array}$ & $\begin{array}{c}\text { Antihistamínico y } \\
\text { corticoide oral }\end{array}$ & \\
\hline
\end{tabular}

RAA: reacciones alérgicas a alimentos; PC: prueba cutánea; AINE: antiinflamatorios no esteroideos; LTP: proteínas transportadoras de lípidos; CCD: determinantes de reactividad cruzada de carbohidratos. 
TABLA 3. Descripción de los pacientes y su evolución

\begin{tabular}{|c|c|c|c|c|c|c|}
\hline $\mathbf{N}^{\circ}$ & Edad & Sexo & Panalergeno & $\begin{array}{l}\text { Alimentos } \\
\text { implicados }\end{array}$ & Clínica & $\begin{array}{c}\text { Evolución } \\
\text { con evitación }\end{array}$ \\
\hline 1 & 16 & $\mathrm{H}$ & LTP & Melocotón, nuez & AIEDA & Sin RAA \\
\hline 2 & 15 & $\mathrm{H}$ & LTP & Rosáceas, melón, kiwi & $\begin{array}{c}\text { RAA } \\
\text { POLEN }\end{array}$ & Sin RAA \\
\hline 3 & 6 & $\mathrm{H}$ & LTP & $\begin{array}{l}\text { Melocotón, manzana, albaricoque, } \\
\text { almendra, cacahuete }\end{array}$ & RAA & Sin RAA \\
\hline 4 & 3 & $\mathrm{H}$ & LTP PROFILINA & Melocotón, palomitas de maíz & RAA & Sin RAA \\
\hline 5 & 14 & $\mathrm{H}$ & LTP & Rosáceas, frutos secos & RAA & Sin RAA \\
\hline 6 & 14 & M & PROFILINA & Lenteja, alubia & $\begin{array}{c}\text { RAA } \\
\text { POLEN }\end{array}$ & Sin RAA \\
\hline 7 & 16 & $\mathrm{H}$ & NEGATIVO & Nueces & AIEDA & Sin RAA \\
\hline 8 & 16 & M & NEGATIVO & Crema con cacao y avellana & AIEDA & Sin RAA \\
\hline 9 & 16 & $\mathrm{H}$ & LTP PROFILINA CCD & Patata, pimiento, espárrago, melón & AIEDA & Sin RAA \\
\hline 10 & 5 & $\mathrm{H}$ & LTP & Cacahuete & AIEDA & Sin RAA \\
\hline 11 & 13 & M & PROFILINA & Manzana, piña, melón, sandía, kiwi & RAA & $\begin{array}{l}\text { POLEN } \\
\text { RAA }\end{array}$ \\
\hline 12 & 13 & $\mathrm{H}$ & LTP PROFILINA & Plátano, látex & RAA POLEN & Sin RAA \\
\hline 13 & 14 & $\mathrm{H}$ & PROFILINA CCD & Frutos secos, rosáceas, kiwi & RAA & RAA \\
\hline 14 & 2 & $\mathrm{H}$ & LTP PROFILINA & $\begin{array}{l}\text { Tomate, kiwi, cítricos, plátano, } \\
\text { ciruela, frutos secos, maíz }\end{array}$ & RAA & Sin RAA \\
\hline 15 & 15 & M & BET V1 & $\begin{array}{l}\text { Manzana, nectarina, cereza, } \\
\text { melocotón, pera, avellana }\end{array}$ & RAA POLEN & Sin RAA \\
\hline 16 & 8 & M & LTP & Frutos secos, manzana, cereza, nectarina & RAA & Sin RAA \\
\hline 17 & 12 & $\mathrm{H}$ & LTP PROFILINA & Pipa de girasol & $\begin{array}{c}\text { RAA } \\
\text { POLEN }\end{array}$ & Sin RAA \\
\hline 18 & 16 & M & LTP & Melocotón & RAA & Sin RAA \\
\hline 19 & 10 & M & PROFILINA & $\begin{array}{l}\text { Albaricoque, melón, nectarina, } \\
\text { manzana, ciruela }\end{array}$ & $\begin{array}{l}\text { RAA ASMA } \\
\text { (ÁCAROS) }\end{array}$ & Sin RAA \\
\hline 20 & 13 & $\mathrm{H}$ & BET V1 & Manzana, melocotón & $\begin{array}{c}\text { RAA } \\
\text { POLEN }\end{array}$ & Sin RAA \\
\hline 21 & 7 & M & LTP & Garbanzo & RAA & Sin RAA \\
\hline 22 & 6 & M & NEGATIVO & Tomate, kiwi & AIEDA & Sin RAA \\
\hline
\end{tabular}

RAA: reacción alérgica a alimentos; AIEDA: anafilaxia inducida por ejercicio dependiente de alimento; LTP: proteínas transportadoras de lípidos; CCD: determinantes de reactividad cruzada de carbohidratos.

TABLA 4. Distribución de la sensibilización de los pacientes incluidos $(n=22)$

Monosensibilización ( $n=13)$

Polisensibilización $(n=6)$

Todas las pruebas realizadas negativas

$\begin{array}{cc}\text { BET V1 } & 2(9,1 \%) \\ \text { LTP } & 8(36,4 \%) \\ \text { PROFILINA } & 3(13,6 \%) \\ \text { CCD } & 0(0,0 \%) \\ \text { LTP + PROFILINA } & 3(13,6 \%) \\ \text { PROFILINA + CCD } & 1(4,5 \%) \\ \text { LTP + PROFILINA + CCD } & 2(9,1 \%) \\ & 3(13,6 \%)\end{array}$

LTP: proteínas transportadoras de lípidos; CCD: determinantes de reactividad cruzada de carbohidratos. 
asuman estos síntomas con tal de no alterar sus hábitos, aunque, dada la limitada muestra, es difícil establecer conclusiones.

En nuestra muestra, como en el sur de Europa, ${ }^{6}$ la sensibilización más frecuentemente encontrada es frente a LTP, seguido de la profilina. Los pocos casos de pacientes con alergia a Bet v1 son monosensibles.

Entre los pacientes monosensibles, se observó gran variabilidad en la respuesta clínica frente a alimentos vegetales. Por ello y por el escaso número de pacientes, no se pudo definir un patrón común de respuesta de cada grupo que sugiriera algún conjunto de alimentos de mayor o menor riesgo para pacientes alérgicos a cada panalergeno estudiado, exceptuando frutas rosáceas y frutos secos en casos de alergia a LTP.

En este estudio, no se estableció ninguna técnica de enmascaramiento ni grupo control.

\section{CONCLUSIONES}

Estos resultados preliminares sugieren que la utilización del diagnóstico por componentes aplicado en esta patología en la edad infantil podría ser útil para la reducción de las reacciones alérgicas alimentarias, especialmente graves. Son necesarios estudios con muestras y seguimientos más prolongados para confirmar esta hipótesis.

\section{REFERENCIAS}

1. Borres MP, Ebisawa M, Eigenmann PA.Use of allergen components begins a new era in pediatric allergology. Pediatr Allergy Immunol 2011;22(5):454-61.

2. Wolthers OD. Component-Resolved Diagnosis in Pediatrics. ISRN Pediatrics 2012;2012:806920.
3. Canonica GW, Ansotegui IJ, Pawankar R, SchmidGrendelmeier P, etal. AWAO-ARIA-GA²LEN consensus document on molecular-based allergy diagnostics. World Allergy Organ J 2013;6(1):17.

4. Hauser M, Roulias A, Ferreira F, Egger M. Panallergens and their impact on the allergic patient. Allergy Asthma Clin Immunol 2010;6(1):1.

5. Pastorello EA, Robino AM. Clinical role of lipid transfer proteins in food allergy. Mol Nutr Food Res 2004;48(5):356-62.

6. Fernández-Rivas M, Bolhaar S, González-Mancebo E, Asero R, et al. Apple allergy across Europe: how allergen sensitization profiles determine the clinical expression of allergies to plant foods. J Allergy Clin Immunol 2006;118(2):481-8.

7. Cudowska B, Kaczmarski M. Diagnostic value of birch recombinantallergens (rBetv 1, profilin rBetv 2) in children with pollen-related food allergy. Rocz Akad Med Bialymst 2004;49:111-5.

8. Asero R, Monsalve R, Barber D. Profilin sensitization detected in the office by skin prick test: a study of prevalence and clinical relevance of profilin as a plant food allergen. Clin Exp Allergy 2008;38(6):1033-7.

9. Soh JY, Huang $\mathrm{CH}$, Lee BW. Carbohydrates as food allergens. Asia Pac Allergy 2015;5(1):17-24.

10. Sicherer SH, Sampson HA. Food allergy. J Allergy Clin Immunol 2010;125(2 Suppl 2):S116-25.

11. García BE, Lizaso MT. Cross-reactivity syndromes in food allergy. J Investig Allergol Clin Immunol 2011;21(3):162-70.

12. VieiraT,Cunha L, Neves E, FalcãoH. Diagnostic usefulness of component-resolved diagnosis by skin prick tests and specific IgE to single allergen components in children with allergy to fruits and vegetables. Allergol Immunopathol (Madr) 2014;42(2):127-35.

13. Berni Canani R, Leone L, D'Auria E, Riva E, et al. The effects of dietary counseling on children with food allergy: a prospective, multicenter intervention study. J Acad Nutr Diet 2014;114(9):1432-9.

14. Cardona V, Luengo O, Garriga T, Labrador-Horrillo $\mathrm{M}$, et al. Co-factor-enhanced food allergy. Allergy 2012;67(10):1316-8.

15. Niggemann B, Beyer K. Factors augmenting allergic reactions. Allergy 2014;69(12):1582-7. 